\title{
A relação entre raça e educação na obra de Gilberto Freyre ${ }^{1}$
}

\section{Amurabi Oliveira ${ }^{2}$}

Universidade Federal de Santa Catarina, Florianópolis, Brasil ${ }^{3}$ amurabi_cs@hotmail.com

Recibido: 28 de noviembre de 2014

Aceptado: 14 de mayo de 2015

Disponible en linea: 30 de noviembre de 2015

1 Artigo de Reflexão apresenta parte dos resultados parciais de uma investigação mais ampla sobre a questão educacional na obra de Gilberto Freyre, que vem sendo desenvolvida em articulação com as disciplinas de Pensamento Social Brasileiro e Sociologia da Educação junto à graduação de Ciências Sociais e ao Programa de Pós-Graduação em Sociologia Política da Universidade Federal de Santa Catarina. Visa, sobretudo, explorar e aprofundar um aspecto pouco discutido no legado intelectual freyreano, e de forma mais ampla contribuir para a discussão sobre a questão educacional no Pensamento Social Brasileiro.

2 Doutor em Sociologia pela Universidade Federal de Pernambuco (UFPE).

3 Atualmente é professor da Universidade Federal de Santa Catarina, atuante em seu Programa de Pós-Graduação em Sociologia Política. 


\title{
A relação entre raça e educação na obra de Gilberto Freyre
}

\section{Resumo}

Gilberto Freyre (1900-1987) foi um dos mais importantes pensadores sociais brasileiro, cujo legado tem sido constantemente revisitado. Nesse trabalho volto-me a um aspecto pouco explorado de sua obra que diz respeito à relação entre educação e raça. Indico nesse texto que para além do 'mito da democracia racial' Freyre reconhece os entraves e desigualdades existentes na sociedade brasileira, tanto que chega a afirmar que os diplomas se tornam verdadeiras 'cartas de branquitude sociológicas', reconhecendo não apenas o profundo fosso social existente entre brancos, negros e mulatos no Brasil, como também chamando a atenção para a dinamicidade criada com o processo paulatino de escolarização. Analiso como na obra de Freyre se apresenta essa relação entre ascensão social dos negros e mulatos e a educação, o que realizado utilizando como substrato principalmente os autores que têm produzido conhecimento no campo do pensamento social brasileiro.

Palavras-chaves: Gilberto Freyre; Pensamento social brasileiro; raça e educação

\section{The Relation Between Race and Education in the Work of Gilberto Freyre}

\begin{abstract}
Gilberto Freyre (1900-1987) was one of the most important Brazilian social thinkers, whose legacy has been constantly revisited. In this paper I turn to a relatively unexplored aspect of his work that concerns the relationship between education and race. I point in this text beyond the 'myth of racial democracy' Freyre recognizes the existing barriers and inequalities in Brazilian society, so much that even states that diplomas become true 'letters of sociological whiteness"' recognizing not only the deep social differences existing between whites, blacks and mulattos in Brazil, as well as drawing attention to the dynamics created with the gradual process of schooling. I analyze how the work of Freyre presents this relationship between social mobility of blacks and mulattos and education, which I do using as substrate mainly the authors who have produced knowledge in the field of Brazilian social thought.
\end{abstract}

Keywords: Gilberto Freyre; Brazilian social thought; race and education

\section{La relación entre raza y educación en la obra de Gilberto Freyre}

\section{Resumen}

Gilberto Freyre (1900-1987) fue uno de los más importantes pensadores sociales de Brasil, cuyo legado ha sido revisado constantemente. En este trabajo me dirijo a un aspecto poco explorado de su obra que se refiere a la relación entre la educación y la raza. Señalo en este texto que más allá del 'mito de la democracia racial', Freyre reconoce las barreras y desigualdades existentes en la sociedad brasileña, tanto es así que incluso se afirma que los títulos se convierten en verdaderas 'cartas de blancura sociológicas', reconociendo no solo la profunda brecha existente entre blancos, negros y mulatos en Brasil, sino que llama la atención sobre la dinámica creada con el proceso gradual de escolaridad-escolarización. Analizo cómo el trabajo de Freyre presenta esta relación entre la movilidad social de los negros y mulatos y la educación. Llevo esto a cabo utilizando como sustrato principalmente los autores que han producido conocimiento en el campo del pensamiento social brasileño. Palabras clave: Gilberto Freyre; pensamiento social de Brasil; raza y educación 


\section{Introdução}

$\mathrm{Na}$ recente produção bibliográfica das Ciências Sociais brasileiras Gilberto Freyre (1900-1987) é de longe um dos autores mais citados e referenciados (Melo, 1999; Costa, 2010), em que pese o fato de ter tido uma carreira acadêmica bastante sui generis com experiências pontuais de vinculos institucionais com universidades. Porém, a impressão que se passa ao considerarmos a contínua e persistente referência a seu trabalho é que as questões por ele lançadas, principalmente a partir da publicação de Casa Grande y Senzala em 1933, ainda não foram suficientemente respondidas.

Mas também é importante lembrar ao leitor que a referência ao trabalho de Freyre se dá de forma bastante diversa, tendo em vista que toda sua carreira foi marcada por uma intensa polêmica sobre o que escreveu e como escreveu. Foi objeto de questionamento não apenas sua interpretação sobre o Brasil, especialmente no que diz respeito às relações raciais, como também a forma como forjou seu trabalho, seja em termos metodológicos, seja em termos de estilo de escrita.

O ápice da polêmica envolvendo seus escritos diz respeito ao fato de que o autor seria o principal defensor da ideia de que haveria no Brasil uma 'democracia racial', de modo que têm sido atribuídas continuamente a Freyre, de forma certa ou errada, a elaboração e difusão do 'mito da democracia racial' (Motta, 2000). Neste texto não entrarei em um debate mais intenso sobre essa questão, até mesmo porque ela já vem sendo exaustivamente discutida no Brasil. O que procurarei realizar nesse trabalho é analisar um aspecto da obra de Freyre ainda pouco examinado por seus intérpretes, que diz respeito à relação entre educação e ascensão social de negros e mulatos; com isso não significa que me eximirei de um exame mais crítico sobre o legado de Freyre, contudo esse não será meu foco.

Apesar de esse ser um tema que vem se desdobrando em inúmeras discussões no campo dos estudos sobre desigualdades sociais e educação, não pretendo aqui dialogar com esta literatura, ainda que reconheça sua relevância, tendo em vista que meu foco circunscreve-se nesse 
momento ao Pensamento Social Brasileiro, buscando elucidar um ângulo insuficientemente explorado pelos pesquisadores que se dedicam ao reexame da obra de Freyre, não se trata, portanto, de um artigo que visa validar ou não as ideias do autor frente a uma realidade empírica, tal escolha se deve ao enfoque aqui adotado, bem como o reconhecimento dos limites desse artigo.

Neste caso não estamos no campo da Sociologia da Educação, mas sim da História das Ideias Sociológicas, reconhecendo o crescente processo de incrementação das pesquisas na área do Pensamento Social Brasileiro nas últimas décadas, que passa a se consolidar como um campo intelectual cada vez mais autônomo das Ciências Sociais (Bastos y Botelho, 2010), sendo assim, meu referêncial teórico baseia-se no próprio Freyre e naqueles que têm se proposto a reanalizar seu trabalho.

Para uma melhor organização das ideias, dividirei esse artigo em duas partes, na primeira apresentarei o autor dando destaque para sua interpretação do Brasil e de suas relações raciais, e na segunda focarei na relação entre educação, raça e ascensão social. Anuncio desde já minha hipótese de trabalho que acredito ser a principal contribuição para o debate: a partir do momento em que Freyre examina o processo de ascensão social de negros e mulatos na sociedade por meio da educação há um reconhecimento aí de uma sociedade desigual em termos raciais, uma vez que a mobilidade social pressupõe estratificação, e neste caso trata-se de uma estratificação que tem por base a questão da cor.

Ao me voltar para um autor clássico do Pensamento Social Brasileiro não procuro me situar simplesmente numa discussão no âmbito da História das Ideias, mas sim pensar também na atualidade das questões postas, uma vez que compartilho da posição de Bastos (2002, p. 183) acerca da relevância de revisitarmos os autores clássicos das Ciências Sociais brasileiras, pois "[...] sem compreender tanto as ideias como o lugar social desses intelectuais é impossivel apreender o movimento geral da sociedade brasileira". 


\section{O Gilberto Freyre e o Brasil}

Não há como realizar uma separação entre as ideias formuladas por Freyre em seu processo interpretativo do Brasil e sua trajetória, neste sentido eu confluo com as conclusões as quais chegou Freitag (2005), que ao analisar o pensamento de Gilberto Freyre, Florestan Fernandes (1920-1195) e Celso Furtado (1920-2004) que acabou por se aproximar em sua interpretação da "[...] tese marxista que nossa Weltanschauung (visão de mundo) é reflexo das condições materiais em que vivemos. Das Sein bestimmt das Bewusstsein, ou seja, o ser determina a consciência". (Freitag, 2005, p. 236)

Nascido em Recife, capital de Pernambucano, no último ano do século XIX, Freyre descende de uma aristocracia rural que fora central em um mundo que não mais existia aquele tempo, afinal, estamos nos referindo a um Brasil pós-abolição e pós império, que buscava se modernizar em termos sociais, políticos e econômicos. Recife, ou o Recife como preferia o autor (Freyre, 1967), já não ocupava o lugar de destaque que possuíra durante o ápice do 'ciclo do açúcar', havia ocorrido uma intensa mudança no eixo político, econômico e social do país.

Quem lê o trabalho de Freyre além da sensação de ficar continuamente inebriado, pois o seu fazer científico se realizava por meio de uma elaboração complexa de palavras que soavam como literatura, nota também um ar levemente nostálgico de um país que não mais existia. Para o estudioso pernambucano a saudade se constituía como um método empático de fazer reviver um tempo morto (Villas Boas, 2006), se articulando também com sua intuição, que seria um dos alicerces de seu fazer científico (Freyre, 1968).

Para além de suas experiências na infância que foi revisitada em alguns de seus trabalhos como Tempo morto e outros tempos (2012), acredito que é de fundamental relevância pensarmos aqui nas experiências acadêmicas vivenciadas pelo autor ainda jovem, pois elas serão decisivas para compreendermos a posição que ele assume para a compreensão do país. 
É bastante conhecido o fato de que Freyre teve parte de sua formação intelectual ainda na infância e adolescência no Colégio Americano Batista do Recife, para Larreta e Giucci (2007, p. 43): “pode-se considerar a experiência de Gilberto Freyre no Colégio Americano como uma das matrizes da formação de seu caráter". A continuação de seus estudos nos Estados Unidos -o que era pouco usual para a área de humanidades naquele período, no qual ainda figurava uma ampla hegemonia das Universidades europeias-, representou, em alguma medida, um caminho "natural" com relação à educação recebida em Recife, o que fica ainda mais evidente se considerarmos a instituição para a qual ele seguiu: a Universidade de Baylor, em Waco-Texas, que tinha uma tradição de receber alunos vindos de Recife.

A vivência no Sul dos Estados Unidos foi algo seminal em sua constituição intelectual, tendo em vista que esta realidade passa a ser um ponto de comparação com o Brasil (Pallares-Burke y Burke, 2009), sendo relevantes tanto os pontos comuns quanto os divergentes, pois tal exercício comparativo possibilitava compreender os efeitos mais amplos da escravidão em uma sociedade assentada economicamente na monocultura, no latifúndio e na família patriarcal, ao mesmo tempo em que através desse recurso o autor visibilizava as particularidades da sociedade brasileira, o que a tornava única em termos étnicos e sociais.

Entretanto ganha força em suas memórias intelectuais sua outra experiência acadêmica na América do Norte, mais especificamente na Universidade de Columbia, em Nova York. Essa prática será utilizada retoricamente em vários de seus trabalhos, incluindo aí o prefácio da primeira edição de Casa Grande y Senzala, quando afirma que "O professor Franz Boas é a figura de mestre de que me ficou até hoje maior impressão. Conheci-o nos meus primeiros dias em Colúmbia." (Freyre, 2005, p. 31). Essa referência é bastante conhecida, porém Motta (2008) chega a questionar em que medida ela representa a realidade, tendo em vista que Franz Boas (1858-1942) não foi orientador no sentido formal do termo de Freyre e que este realizou seu mestrado em História Social não em Antropologia ${ }^{4}$.

4 Seu trabalho de mestrado intitulou-se Social life in Brazil in the middle of the 19th century e foi publicado no periódico Hispanic American Historical Rewiew, volume 5. 
Motta e Fernandes (2013) problematizam por que Freyre, pelo menos desde a publicação de Casa-grande y Senzala, teria optado por destacar o legado de Boas em detrimento de seu relacionamento com Carlton Hayes, que fora seu orientador nos estudos de pós-graduação. Para estes intérpretes a filiação que Freyre passa a reivindicar se liga a questões subjetivas e objetivas do autor, que adentram tanto a possibilidade de se destacar academicamente ao se aproximar da Sociologia e da Antropologia, quanto à influência real que Boas exerceu sobre sua obra, em que pese outras múltiplas influências como a de Charles Maurras (1868-1952).

Em verdade ao considerarmos a formação que ele recebeu em Columbia fica claro que a sua vocação transdisciplinar estava posta desde já, uma vez que realizou cursos diversos nesta instituição. Segundo os dados de Pallares-Burke (2005), ele realizou seis cursos de História, dois de Lei Pública, dois de Sociologia, dois de Antropologia, um de Inglês e um de Belas-artes.

Creio que é relevante destacar ainda as condições objetivas que estavam postas quando Freyre voltava para o Brasil em 1923, pois entre os anos de 1920 e 1930 ocorreram intensas mudanças políticas e sociais no país, o que incluiu Reformas Educacionais capitaneadas por alguns intelectuais, como foi no caso da Pernambuco aquela posta a cabo por Carneiro Leão (1887-1966), que introduziu a Sociologia no curso de formação de professores junto à Escola Normal de Pernambuco, tendo sido Freyre aquele que em 1928 é indicado para assumir a cátedra dessa disciplina (Freyre, 2003), o mesmo se procedeu em outras partes do país, portanto, tratava-se de um momento de ascensão das Ciências Sociais no campo acadêmico brasileiro ${ }^{5}$.

Para além de sua formação intelectual fora do país há de se considerar ainda as questões que estavam postas na agenda dos intelectuais brasileiros nos anos de 1920. Nesse sentido são elucidativas as questões postas por Bastos (2006) que indica a existência no ensaísmo desse período duas temáticas centrais: a questão da cultura e a

Para uma melhor análise tanto da experiência docente de Gilberto Freyre quanto de seu lugar no processo de institucionalização da Sociologia no Brasil vide o trabalho de Meucci (2008). 
busca da identidade nacional. Os autores desse periodo procuravam 'inventar a cultura' para legitimar a 'invenção' da identidade nacional, ainda segundo a autora teria sido Freyre aquele que realizou um salto nos estudos sociais ao conseguir articular esses dois elementos.

No processo interpretativo do país a questão racial tornou-se algo central, compreender a nação era desvelar seus dilemas raciais, o que não era algo exclusivo do Brasil, pois como nos indicam Vigoya e Espinel (2014):

En el caso de América Latina, el espacio político concedido a los problemas de raza y racismo fue importante en el momento de conformar las nuevas naciones que debieron lidiar de distintas formas con el dilema que les planteaba la composición racial de sus poblaciones -visiblemente mezcladas- y el deseo y voluntad de acceder a las ventajas del progreso y la civilización propios de las naciones modernas. (p. 14)

No caso brasileiro ganha visibilidade as teorias arianistas desenvolvidas por alguns intelectuais da passagem do século XIX para o XX, bem como as politicas oficiais de estimulo à migração europeia que confluía com estas ideias (Schwarcz, 1993), e que são solapadas com o trabalho magistral de Freyre, especialmente com Casa-Grande y Senzala, ainda que tenha havido uma recepção profundamente heterogênea desse trabalho, o que inclui o silêncio de Oliveira Viana (1883-1951), um dos mais proeminentes intelectuais no Brasil, abertamente apologético ao arianismo (Freyre, 1968).

Como indica o autor pernambucano no prefácio da primeira edição da monumental obra, dentre os problemas brasileiros o que mais lhe inquietava era o da miscigenação, e é a partir dela, subvertendo o sinal valorativo utilizado até então, que ele tentará compreender o Brasil. Freyre chega a destacar o papel 'civilizador' do negro na sociedade brasileira, sendo este em muitos aspectos superior ao branco, diga-se de passagem o sucesso da colonização portuguesa nos trópicos se deveria, dentre outros aspectos, ao fato dele ser o povo menos europeu da Europa, profundamente miscigenado e plástico, sendo um 
elo de ligação entre a Europa e a África, contando com a importante experiência do contato anterior com os mouros (Freyre, 2011).

Para Degler (1976, p. 20) "Antes de Gilberto Freyre começar a escrever, nos primórdios dos anos de 1930, muitos intelectuais brasileiros envergonhavam-se da mistura racial de seu povo. Mas Gilberto Freyre, quase que sozinho, mudou essa forma de pensar". No entendimento de Cardoso (2013) a calorosa recepção da obra de Freyre, bem como a persistência desta, se deve ao fato de que ele foi capaz de criar um mito sobre nós mesmos, sobre o Brasil, ele seria um dos 'inventores' do Brasil enquanto nação.

No entanto, sua singular interpretação da sociedade brasileira que revolucionou a forma de compreender as relações raciais nesse país também trazia uma profunda ambiguidade, na medida em que afirmava que houve aqui relações mais amenas no tratamento com os escravos, ele chega a falar em algumas passagens em 'doçura', além de que, a miscigenação que ocorreria não apenas no plano biológico como também cultural, esta mesma que possibilitou o surgimento da primeira grande 'civilização nos trópicos', seria aquela que teria amalgamado as relações raciais entre brancos e negros, dentro do que ele denominou de 'equilíbrio de antagonismos'.

O que fora considerado revolucionário em um dado momento histórico passa a ser percebido como profundamente conservador em outro, e esta guinada se acentua ante o desenvolvimento do chamado Projeto UNESCO ${ }^{6}$, e principalmente ao considerarmos os resultados da pesquisa aos quais chegou o grupo capitaneado por Florestan Fernandes e Roger Bastide (1898-1974) em São Paulo, que apontaram justamente para conclusões diversas daquelas existentes no que se convencionou denominar de 'mito da democracia racial' (Fernandes, 2007), cujo maior defensor seria Freyre.

6 Trata-se de um grande projeto de investigação patrocinado pela UNESCO e desenvolvido no Brasil no início dos anos de 1950 que visava investigar as relações raciais no Brasil, mobilizando diversos cientistas sociais brasileiros e estrangeiros que possuiam perspectivas distintas sobre como tais relações se davam (Motta, 2007). 
Em meio ao complexo labirinto de ideias que emergem da vasta produção intelectual freyreana, a questão da ascensão social aparece como uma importante chave analítica, justamente por possuir um duplo aspecto, pois, por um lado ao se voltar para a mobilidade social de negros e mulatos indica uma sociedade mais flexivel no que diz respeito às relações sociais, mas por outro, ao se referenciar à ideia de ascensão reconhece o caráter estratificado e desigual dessa mesma sociedade, havendo uma posição de desvantagem para os 'não brancos'. Há uma íntima relação entre ascensão social e educação, e é justamente este ponto que buscarei explorar na obra de Freyre.

\section{Educação e ascensão social de negros e mulatos}

Para esta segunda parte do trabalho, aquela na qual tento avançar na discussão de forma mais substancial, tomo como fio condutor a "trilogia" concebida por Freyre para entender o Brasil": Casa-Grande e Senzala ([1933] 2005), Sobrados \& Mucambos ([1936] 2006) e Ordem \& Progresso ([1957] 2004), ainda que também eu recorra a outros trabalhos, uma vez que a questão da educação e de sua relação com a ascensão social, especialmente de negros e mulatos, encontra-se dispersa ao longo de sua obra. Ainda que haja uma direção cronológica na explanação do autor se seguirmos os três livros citados, eu não a seguirei rigorosamente, pois minha intenção reside em problematizar a questão e não expô-la de forma linear. Até mesmo porque sobre o pensamento de Freyre pode-se dizer tudo, menos que ele é linear, apresenta-se mais espiralado, com círculos que nem sempre se fecham, e se ele usa da intuição para escrever, creio que essa acaba por ser uma importante ferramenta para interpretá-lo também.

Um importante ponto que deve ser destacado desde já é a centralidade que a categoria patriarcado assume nesse conjunto de trabalhos para a interpretação do Brasil, o que será objeto de crítica por parte

\footnotetext{
O autor pretendia encerrar esse conjunto de livros que constituíam uma ampla interpretação do Brasil com um quarto intitulado Jazigos \& Covas Rasas, que foi anunciado tanto no prefácio da primeira edição de Ordem \& Progresso em sua nota metodológica, quanto na introdução do prefácio da segunda edição de Sobrados \& Mucambos.
} 
de alguns intelectuais, como Holanda que em Raizes do Brasil ([1936] 1995) problematiza a centralidade do patriarcado para a compreensão do Brasil. Esse livro fora publicado no mesmo ano que Sobrados \& Mucambos de tal forma que na introdução da segunda edição, publicada em 1951, porém datada de 1949, há uma tentativa de responder às críticas recebidas, indicando que haveria uma confusão na leitura de seus críticos entre forma e conteúdo, pois, ainda que houvesse alteração em termos de "conteúdo etnográfico" a forma do patriarcado se manteria. É importante lembrar que a segunda edição de Raizes do Brasil foi publicada em 1948 e dialoga, portanto, com a primeira de Sobrados \& Mucambos, porém houve ainda outros textos nos quais Holanda critica a argumentação freyreana como em 'Sociedade Patriarcal'8 em que o autor indica que Freyre teria universalizado uma categoria que se referiria exclusivamente ao Nordeste, alguns críticos posteriormente falarão mesmo de uma universalização de uma realidade própria de Pernambuco (Pallares-Burke y Burke, 2009).

O importante dessa questão é que a família patriarcal seria o núcleo central a partir do qual se irradiaria a sociedade brasileira, sendo também uma unidade autônoma na qual todo um mundo social teria se desenvolvido, o que implica em dizer que também os processos educacionais teriam se irradiado aí, afinal tudo ocorria ali nos domínios da Casa-grande, incluindo a aprendizagem das primeiras letras (Freyre, 2005).

Sendo assim, em que pese as críticas ao processo de universalização da categoria 'patriarcado' ou mesmo 'família patriarcal' na obra de Freyre para a compreensão do Brasil, deve-se considerar a centralidade dela a compreensão do desenvolvimento dos processos educativos que ocorreram no Brasil, pois é no seio da família patriarcal que ocorreria a intensa interprenetração de etnias e culturas, as quais o autor faz referência e isso ocorreria também nos primeiros aprendizados escolares. Os espaços educativos desenvolvidos na família patriarcal, família extendida e poligâmica na compreensão de Freyre, teriam como característica, por vezes, uma 'co-educação' entre negros, mulatos e brancos (Freyre, 2005), que teria implicações tanto sobre o

8 Este artigo foi publicado na coletânea Tentativas de Mitologia (1979). 
desenvolvimento das relações mais harmoniosas, o que é alvo de intensas críticas, quanto de relações profundamente sádo-masoquistas entre brancos e negros/mulatos.

O sistema de co-educação que teria se desenvolvido desde os primórdios da família patriarcal brasileira seria, portanto, um relevante argumento para Freyre na indicação de quão singulares teriam sido as relações raciais no Brasil, o que possui como ponto comparativo constante a região Sul dos Estados Unidos.

No entanto, quando examinamos mais de perto, podemos perceber que no que diz respeito à questão educacional temos um cenário um pouco mais complexo, pois para além da Casa-grande havia a concorrência dos Jesuítas, que ocuparam uma posição central e inquestionável no desenvolvimento das práticas pedagógicas do Brasil, principalmente até às reformas pombalinas no século XVIII ${ }^{9}$ (Saviani, 2011).

Temos assim um cenário bifurcado em termos analíticos para Freyre que se vincula a maior polêmica presente em seu trabalho, que é a possibilidade de haver ou não uma democracia étnica no Brasil. Nesse ponto creio que é importante indicar que o Brasil representaria, na perspectiva de Freyre, aquela nação que teria chegado mais perto de uma democracia étnica, ainda que se tratasse de uma democracia imperfeita, pois o racismo persistiria entre nós. Entretanto essa afirmativa só ganha valor em termos comparativos, principalmente quando consideramos a realidade americana, marcada por uma evidente separação entre brancos e negros, diferenciando-se do Brasil, ainda na leitura do autor, pela ausência (ou pouca) miscigenação.

A educação vivenciada na Casa-grande diferenciava-se da existente entre os jesuítas devido à presença da co-educação entre negros e brancos, o que seria reativamente recorrente, pois segundo Freyre (2011, p. 108) "Era comum, entre os senhores de engenho, educar

9 O Marques de Pombal (1699-1782) foi Secretário de Estado do Reino de Portugal tendo promovido uma série de Reformas, dentre as quais se destaca no campo educacional a expulsão dos Jesuitas em 1759 cujas atividades pedagógicas no nível mais elementar de ensino foram substituídas pelas chamadas Aulas Régias, financiadas pelo governo português. Essas reformas também atingiram o ensino superior, uma vez que os Jesuítas ocupavam um lugar central na formação universitária. 
filhos mulatos, ou ilegitimos, dando-lhes a mesma instrução que aos legitimos desde que mostrassem talento ou gosto pelas letras", ao passo em que os jesuitas não teriam contribuído para a formação de uma democracia étnica no país ao impossibilitarem a existência dessa prática, voltando sua ação pedagógica para os brancos e índios apenas (Freyre, 2001).

Obviamente que podemos problematizar essa perspectiva, uma vez que a proximidade física não necessariamente eliminaria o fosso social existente, porém, o relevante aqui é destacar que para o autor a forma como a educação teria sido conduzida no Brasil contribuiria para a consolidação de nossa 'democracia étnica'. Mais que isso, se reconhecemos que em Freyre há uma concepção 'neolamarckiana' de raça, cujas características receberiam uma influência decisiva do meio (Araújo, 1994), a 'inclusão' dos negros e mulatos nas práticas educativas que teriam sido realizadas no Brasil possuiriam um impacto direto sobre as características destes grupos étnicos. Em alguma medida podemos afirmar que a gênese da ascensão social de negros e mulatos, por meio da educação que Freyre observa a partir das mudanças sociais que teriam ocorrido no Brasil, encontrar-se-ia desde a formação da família patriarcal, ainda que as condições sociais para a sua realização plena só viria a ocorrer na República.

Tendo em vista essa posição, compreendo que o sistema de co-educação, ou ao menos sua possibilidade, é uma chave analítica profundamente relevante no pensamento de Freyre, pois ele ao mesmo tempo se faz possivel devido à postura que os portugueses tinham com relação às questões raciais, sua plasticidade que se explicara por meio do processo histórico de constituição de Portugal enquanto nação (Freyre, 2005), mas também esse sistema seria um promotor da democracia étnica.

A afirmação categórica que os jesuítas não contribuíram para a formação de uma democracia étnica no Brasil ao negar a co-educação entre negros e brancos significa em primeiro lugar que Freyre reconhece a desigual posição que esses sujeitos ocupavam na estrutura social, pois havia uma democracia que estava por se constituir e não 
simplesmente dada, e em segundo que a educação poderia ser compreendida como uma importante ferramenta nesse processo.

O equilíbrio de antagonismos existente na leitura do autor não poderia se manter exclusivamente em cima da miscigenação, apesar de seu papel central para tanto, seria necessário um conjunto de condições sociais para que ele se efetivasse, compreendo dessa forma que o acesso à educação por parte não apenas dos brancos seria um dos fatores presente nesse conjunto.

Antes que passemos para questão seguinte é relevante voltar mais uma vez para o contexto no qual o autor se situava, pois os anos de 1930 também representaram um período de rápidas mudanças educacionais, basta pensarmos no impacto que teve a publicação do Manifesto dos Pioneiros da Educação Nova em 1932, que apregoavam que os sujeitos deveriam ter acesso à educação até onde fossem seus limites biológicos, convocando o Estado para a promoção dessa missão. Freyre, de algum modo, possuía certa proximidade com esse grupo, o que pode ser atestado por meio de sua atuação como professor de Sociologia junto à Escola Normal de Pernambuco durante as Reformas Educacionais promovidas por Carneiro Leão no final dos anos de 1920, bem como através relação com Anísio Teixeira, que o convida para ser professor na Universidade do Distrito Federal nos anos de 1930 e diretor do Centro Regional de Pesquisas Educacionais do Recife nos anos de 1950 (Oliveira, 2014b).

Havia um rápido incremento das populações que passavam a demandar pela Educação Básica, o que foi acompanhado pelo debate sobre o lugar delas no sistema de ensino, propulsionado pelos laboratórios de Psicologia e Antropologia Pedagógica (Oliveira, 2013). Na passagem do século XIX para o XX ainda se colocava em pauta no Brasil a discussão sobre a suposta inferioridade intelectual do negro com relação ao branco, o que encontrou ecos ainda durante a primeira metade do século passado. Nesse ponto creio que a contribuição do debate inaugurado por Freyre foi fundamental para pensarmos as possibilidades de inserção dos negros no sistema escolar, pois o autor buscou delimitar claramente as diferenças existentes entre as características 
que eram consideradas como próprias dos negros e aquelas que remetiam à condição de escravo.

Neste ponto é relevante indicar que a influência das discussões que estavam sendo realizadas naquele período na Antropologia americana e repercutem na obra de Freyre, especialmente a partir do culturalismo, o que contrastava com as influências intelectuais mais preponderantes nos meios intelectuais brasileiros na mesma época. Pois, se a intelectualidade brasileira discutia a capacidade do negro se inserir ou não no sistema escolar formal, dada suas limitações cognitivas, na leitura de alguns pensadores do período (Freitas, 2005), Freyre (2005) pontua que as características negativas atribuídas ao negro não eram inerentes à raça, mas sim reflexo da condição de escravo, portanto, eram produzidas socialmente, de forma articulada com o meio. Na verdade, de acordo com Freyre, o negro seria superior ao branco em diversos aspectos físicos e morais.

Ademais, em meio a uma realidade social na qual o analfabetismo era a regra e não a exceção, Freyre enfatizou a presença de escravos que sabiam ler e escrever, especialmente os escravos islamizados (Freyre, 2005), o que se opunha à figura do senhor da Casa-grande -ignorantes em termos de instrução, porém senhores absolutos em termos de poder político e social.

Estas ideias, com relação à instrução dos negros no Brasil, amadurecem paulatinamente nos trabalhos do autor aqui examinado, porém esses processos aos quais ele faz referência estão ligados aos movimentos mais amplos de mudança da sociedade. Uma vez que a educação não era o centro no universo patriarcal, é com a passagem para o Império e posteriormente República que a Educação passa a ser uma real possibilidade de ascensão social na interpretação do autor, ainda que ele afirme que mesmo durante o 'sistema de plantação' não havia 'rígidas gradações sociais', sendo possivel aos sujeitos, ainda que de origem social humilde, a ascensão social.

É interessante notar que é na obra Sobrados \& Mucambos que Freyre escreve um capitulo intitulado "Ascensão do bacharel e do 
mulato", que estava presente desde a primeira edição do livro. Neste capítulo, Freyre aponta que os dois "personagens" emergem de forma visceralmente entrelaçadas, ou seja, a ascensão social do mulato se faz possivel na medida em que outras formas de ascensão social ganham espaço na sociedade brasileira, e estas não dependeriam estritamente de outros fatores, como a posse de terras no regime colonial.

Chama a atenção que no título desse capítulo Freyre refira-se ao mulato e não ao negro. Este havia sido objeto exclusivo de análise em dois dos cinco capitulos de Casa-Grande y Senzala, o que nos leva a uma problematização sobre o lugar especial que o mulato ocupa nessa nova sociedade que emergia. Compartilho da compreensão de Degler (1976, p. 234) de que "a 'saída de emergência' do mulato serve como símbolo, na verdade como condensação, de uma gama de relações entre pretos e brancos e das atitudes de um para com o outro", sendo assim o destaque dado pelo autor indica, no final das contas, que seu olhar se volta para aquele que sintetiza o movimento mais amplo da sociedade brasileira, cuja marca primeira seria a miscigenação biológica e cultural.

O mulato seria a sínteses dos novos tempos, e se no regime de plantação a possibilidade do acesso à instrução se dava a partir da concessão realizada pelo senhor de engenho, normalmente feita a seus filhos bastardos; a partir do século XIX com o avanço do espaço urbano, ainda que houvesse uma reacomodação das estruturas sociais, mesmo aqueles oriundos de famílias mais pobres teriam a possibilidade de ter acesso à instrução, o que por consequência possibilitaria a ascensão social, e neste contexto a profissão de professor representou uma das possibilidades de angariamento de um maior prestígio social por parte de mulatos pobres (Freyre, 2003). Ainda segundo o autor:

Desde os últimos tempos coloniais que o bacharel e o mulato vinham se constituindo em elementos de diferenciação, dentro de uma sociedade rural e patriarcal que procurava integrar-se pelo equilíbrio, e mais do que isso, pelo que os sociólogos modernos chamam acomodação, entre dois grandes antagonismos: o senhor e o escravo (Freyre, 2006, p. 710). 
O mulato e o bacharel seriam dessa forma os protagonistas do país que se urbanizava. Para Freyre, os letrados (os bacharéis) foram figuras centrais nesse período, tanto que algumas das principais revoltas do período, como a Inconfidência Mineira ${ }^{10}$, teria sido uma revolta de bacharéis.

Esses novos agentes representavam a antinomia dos antigos senhores de engenho, especialmente os bacharéis, que, ao regressarem ao país com sua formação europeia -pois os primeiros cursos superiores surgem no Brasil apenas no começo do século XIX-, acentuavam "[...] nos pais e avós senhores de engenho, não só o desprestígio da idade patriarcal, por si só uma mística, como a sua interioridade de matutões atrasados" (Freyre, 2006, p. 713).

Pensando especificamente a relação entre a questão racial e a educação em Ordem \& Progresso acredito que Freyre radicaliza ainda mais seu argumento, ao indicar que:

[...] desde o Império os títulos acadêmicos foram no Brasil meios de ascensão social que favoreceram particularmente os moços mestiços ou de origem modesta. Eram cartas de branquitude sociológica que os foram tornando iguais aos brancos de origem fidalga: às vezes seus superiores pelo talento e pelo saber aplicado à política, à advocacia, à medicina, ao sacerdócio, à engenharia: a atividades socialmente prestigiosas.

Esse processo de valorização do homem de origem modesta ou de condição étnica socialmente inferior, pelo título acadêmico, acentuou-se com o advento da República; e não apenas através das referidas academias ou escolas superiores, como através das academias ou escolas militares. Não tanto a da Marinha como a do Exército. Embora continuando, neste ponto, a obra do Império, e não propriamente inovando na matéria, a República avivou no Brasil as oportunidades de ascensão social, particularmente política, dos mestiços e dos plebeus. (Freyre, 2004, p. 536)

${ }^{10}$ Movimento de caráter separatista do Brasil em relação a coroa portuguesa organizado a partir de Minas Gerais no século XVIII, apesar de ter havido outros movimentos com finalidades similares no periodo esse é considerado um dos mais relevantes. 
Ao que parece, a mudança dos tempos implicou uma guinada do lugar da educação na sociedade brasileira, tornando-se cada vez mais central para a definição do lugar social dos agentes, nesse ponto é relevante acrescentar que com o advento da República, período no qual segundo o autor os títulos acadêmicos passam a impactar mais no processo de ascensão social daqueles oriundos de 'condição étnica socialmente inferior', amplia-se paulatinamente o acesso ao sistema de ensino, tanto no que se refere à Educação Básica quanto ao Ensino Superior. Isso se torna ainda mais evidente com o fim da chamada 'República Velha' na década de 1930, quando a educação passa a ocupar um lugar ainda mais central no debate político, como pode-se perceber com o advento do Ministério a Educação e Saúde Pública em novembro de 1930, a publicação do Manifesto dos Pioneiros da Educação Nova em 1932,e a criação da Universidade de São Paulo em 1934 e da Universidade do Distrito Federal em 1935, nesta última Freyre chegou a atuar como professor.

O que Freyre consegue captar é que havia mudanças em curso na sociedade brasileira, de tal modo que as novas configurações que o país assumia, notadamente com um crescente processo de industrialização e urbanização, lançavam novas demandas sobre a sociedade, sendo assim, se na sociedade agrária patriarcal a escolarização formal possui um peso diminuto na atribuição do lugar que cada indivíduo ocupava na estrutura mais ampla da sociedade, na nascente sociedade urbano-industrial este passava a ser um elemento determinante.

Notoriamente a possibilidade de negros e mulatos ascenderem socialmente por meio da escolarização formal só se faria possível nesses termos na medida em que haveria no Brasil uma sociedade na qual a questão étnica não seria uma barreira intransponível, o que era ainda mais evidente com o processo de miscigenação, que como o autor argumenta, teria amalgamado as relações raciais aqui existentes.

É ainda relevante o declínio do papel na Igreja no universo educacional, especialmente dos Jesuitas, pois como já vimos de acordo com Freyre eles não teriam contribuído para a formulação de uma democracia étnica no Brasil, abrindo-se assim espaço para uma série de outras 
instituições, com destaque para as escolas militares na passagem do século XIX para o XX, como bem enfatiza o autor em Ordem y Progresso.

Os jesuítas também são alvos de crítica por parte de Freyre no que se refere a seus métodos pedagógicos, tidos como retrógrados, o oposto do que esse autor defendia em matéria educacional, tendo em vista que:

Não seria exagero afirmar que no lastro de seus escritos e ações Freyre propõe uma renovação pedagógica para o Brasil, próxima aos moldes da educação que ele vivenciou nos Estados Unidos, na qual os livros são fundamentais (demandando uma sólida formação científica), porém em repúdio a um ensino livresco, excessivamente abstrato, longe dos problemas sociais reais que subjazem a prática pedagógica. (Oliveira, 2014b, p. 34)

Levando em consideração os argumentos apresentados aqui, compreendo que a grande relevância de adentrarmos neste aspecto da obra do autor, ainda pouco explorada na vasta literatura que tem se proposto a realizar um balanço de seu trabalho, é que a partir da questão educacional podemos vislumbrar o reconhecimento das desigualdades existentes em nossa sociedade considerando o aspecto étnico, e mais que isso, quais as possibilidades possui a educação e que implicações acarreta nesse processo.

A ideia de pensarmos os diplomas escolares como 'cartas de branquitude sociológica' é bastante instigante e complexa. Ao relacionarmos essa questão com o debate contemporâneo sobre ações afirmativas no Brasil, que, como nos indica Sito (2014), envolve uma ampla gama de disputas e controvérsias, veremos que mesmo partindo de pressupostos substancialmente distintos chegam a uma questão similar: a educação é capaz de alterar sensivelmente o lugar dos 'não brancos' na sociedade.

Se a educação é capaz de 'outorgar branquitude' a negros e mulatos e isso implicou em uma ascensão social destes, significa, em última instância, que a ideia de que Freyre seria o defensor da 'democracia racial' no Brasil é no mínimo questionável, ainda que se possa 
problematizar em que termos ele compreendeu as relações raciais entre negros e brancos, já que ele coloca que a miscigenação amenizou tais relações, criando um verdadeiro espaço de confraternização entre a Casa-Grande e a Senzala, o que tem sido questionado e refutado intensamente. Em que pese a reacomodação das estruturas sociais ao longo do tempo, seria ante uma sociedade urbanizada que não apenas as oportunidades educacionais se ampliam, como também seu lugar é ressignificado, possibilitando que o acesso à instrução formal tenha um impacto sobre a estratificação social, porém, isso só seria possivel, na interpretação do autor, dada a inexistência de barreiras étnicas, ou ao menos a fragilidade destas nos termos comparativos que ele se utiliza no decorrer de toda sua obra para pensar o Brasil.

\section{Considerações finais}

Creio que as questões trazidas revelam quão multifacetada é a obra de Freyre. Apesar de significativamente destoante do paradigma de Ciência Social que se tornou hegemônico no Brasil, devido a seu caráter profundamente intuitivo e imagético (Motta, 2009), a obra freyreana nos traz uma série de reflexões ainda atuais.

O acalorado debate que tem havido no Brasil em torno das ações afirmativas, bem como a emergência de outras discussões no campo educacional, envolvendo a questão racial como a lei $\mathrm{n}^{0} 10.639 / 03^{11}$, têm visibilizado como nunca a relação entre educação e as questões raciais, o que reforça ainda mais a ideia da atualidade de Freyre para pensarmos uma série de questões no campo educacional (Oliveira, 2015).

As questões aqui trazidas nos iluminam as transformações vivenciadas nos últimos anos, colocando-as dentro de um plano de uma perspectiva histórica de longa duração, numa análise dentro do que

\footnotetext{
${ }^{11}$ Esta lei torna obrigatório o ensino de história e cultura afro-brasileira em todas as séries da Educação Básica, o que é certamente um avanço, porém ainda há inúmeros entraves para sua efetivação no Brasil, especialmente quando nos referimos a aspectos mais específicos como no que tangencia à questão religiosa (Oliveira, Almirante, \& Nascimento, 2013; Oliveira, 2014a)
} 
Freyre entendia como uma 'Sociologia Genética' (Freyre, 2009), para a qual a compreensão do passado tinha um peso significativo sobre a interpretação do presente, no caso específico do Brasil havia uma clareza por parte do autor de que o passado se fazia presente.

Sendo assim, compreendo que o trabalho de Freyre nos possibilita melhor entender as mudanças que têm ocorrido (e ainda ocorrem) no Brasil em período recente, indicando que o impacto da educação sobre as relações sociais não é algo novo, e que adquire um especial sentido ante a uma sociedade desigual como a nossa. Todavia isso não nos exime de adotarmos uma postura crítica sobre as ideias do autor, ou mesmo questionarmos sua precisão metodológica, ainda que esta última tarefa só possa ser empreendida a partir de outra referência de ciência que amputa de seu corpo a intuição e o imagismo.

\section{Referências}

Araújo, R. B. de (1994). Guerra e Paz: Casa-grande e senzala e a obra de Gilberto Freyre nos anos 30. Rio de Janeiro: Editora 34.

Bastos, E. R. (2002). Pensamento social da escola sociológica paulista. Em Miceli, S. (Org.). O que ler na ciência social brasileira: 1970-2002: Sociologia (pp. 183-230). São Paulo: Sumaré/ANPOCS.

Bastos, E. R. (2006). As Criaturas de Prometeu: Gilberto Freyre e a formação da sociedade brasileira. São Paulo: Global.

Bastos, E. R. y Botelho, A. (2010). Horizontes das Ciências Sociais: Pensamento Social Brasileiro. Em Benedito Martins, C., e de Souza Martins, H. (Eds.). Horizontes das Ciências Sociais no Brasil: Sociologia (pp. 475-496). São Paulo: ANPOCS.

Cardoso, F. H. (2013). Pensadores que Inventaram o Brasil. São Paulo: Companhia das Letras. 
Costa, S. (2010). Teoria como adição. Em Benedito Martins, C., e de Souza Martins, H. (Eds.). Horizontes das Ciências Sociais no Brasil: Sociologia (pp. 20-36). São Paulo: ANPOCS.

Degler, C. N. (1976). Nem Preto Nem Branco: escravidão e relações raciais no Brasil e nos EUA. Rio de Janeiro: Editorial Labor do Brasil.

Fernandes, F. (2007). O Negro no Mundo dos Brancos. São Paulo: Global.

Freitag, B. (2005). Florestan Fernandes revisitado. Estudos Avançados, 19(55), 231-244.

Freitas, M. C. (2005). Alunos Rústicos, Arcaicos \& Primitivos: o pensamento social no campo da educação. São Paulo: Cortez Editora.

Freyre, G. (1967). O Recife, sim! Recife, não! Rio de Janeiro: Arquimedes.

Freyre, G. (1968). Como e porque sou e não sou sociólogo. Brasília: Editora Universidade de Brasília.

Freyre, G. (1979). Tentativas de Mitologia. São Paulo: Perspectiva.

Freyre, G. (2001). Interpretações do Brasil: aspectos da formação social brasileira como processo de amalgamento de raças e culturas. São Paulo: Companhia das Letras.

Freyre, G. (2003). Palauras Repatriadas. Brasilia: Editora da Universidade de Brasília.

Freyre, G. (2004). Ordem \& Progresso: processo de desintegração das sociedades patriarcal e semipatriarcal no Brasil no Brasil sob o regime de trabalho livre: aspectos de um quase meio-século de transição do trabalho escravo para o trabalho livre; e da monarquia para a república. São Paulo: Global.

Freyre, G. (2005). Casa Grande \& Senzala: formação da família brasileira sob o regime da economina patriarcal. São Paulo: Global. 
Freyre, G. ([1936] 2006). Sobrados \& Mucambos: decadência do patriarcado e desenvolvimento do urbano. Global: São Paulo.

Freyre, G. (2009). Sociologia: introdução ao estudo dos seus princípios. São Paulo: Global.

Freyre, G. (2011). Novo Mundo nos Trópicos. São Paulo: Global, 2011.

Freyre, G. (2012).Tempo morto e outros tempos. São Paulo: Global.

Holanda, S. B. (1936/1995). Raizes do Brasil. São Paulo: Companhia das Letras.

Larreta, E. R., y Giucci, G. (2007). Gilberto Freyre: uma biografia intelectual. Rio de Janeiro: Civilização Brasileira.

Melo, M. P. da C. (1999). Quem explica o Brasil. Juiz de Fora: Editora UFJF.

Meucci, S. (2008). Gilberto Freyre e a Sociologia no Brasil: da sistematização à constituição do campo científico. Tese de Doutorado, Programa de Pós-Graduação em Sociologia. Instituto de Filosofia e Ciências Humanas. Campinas: Unicamp.

Motta, R. (2000). Paradigmas de Interpretação das Relações Raciais no Brasil. Estudos Afro-Asiáticos, (38), 113-134.

Motta, R. (2007). Gilberto Freyre, René Ribeiro e o Projeto UNESCO. Em Pereira, C., \& Sansone, L. (Eds.). Projeto UNESCO no Brasil: textos críticos (pp. 38-60.). Salvador: Edufba.

Motta, R. (2008). Reação a Max Weber no Pensamento Brasileiro: O Caso de Gilberto Freyre. Estudos de Sociologia, 2(13), 185-206.

Motta, R. (2009). Élide, Gilberto, Imagismo e Língua de Universidade. Revista Brasileira de Ciências Sociais, 24(68), 185-206.

Motta, R., e Fernandes, M. (2013). Gilberto Freyre, um enigma genealógico. Em Motta, R., e Fernandes, M. (Eds.) Gilberto Freyre: região, tradição, trópico e outras aproximações. (pp. 11-36). Rio de Janeiro: Fundação Miguel de Cervantes. 
Oliveira, A. (2013). O lugar da antropologia na formação docente: um olhar a partir das escolas normais. Pro-Posições, 24(2), 27-40.

Oliveira, A. (2014a). A Vez das Religiões Afro-Brasileiras no Ensino Religioso? as possibilidades e limites abertos pela lei $\mathrm{n}^{\circ}$ 10.639/03. Numen: revista de estudos e pesquisa da religião, 17(1), 171-189.

Oliveira, A. (2014b). Educação e Pensamento Social Brasileiro: alguns apontamentos a partir de Florestan Fernandes e Gilberto Freyre. Revista de Ciências Sociais, 35(1), 15-44.

Oliveira, A. (2015). Gilberto Freyre e a Educação: Raça, Democracia e Ensino de História e Cultura Afro-Brasileiras. Linhas Críticas, 21(43) - prelo.

Oliveira, A., Almirante, K. A., e Nascimento, F. (2013). O Xangô na Sala de Aula: dilemas da identidade religiosa afro-brasileira em Alagoas. Interações: Cultura e Comunidade, 8(14), 261-279.

Pallares-Burke, M. L. (2005). Gilberto Freyre: um vitoriano nos trópicos. São Paulo: Editora Unesp.

Pallares-Burke, M. L. y Burke, P. (2009). Repensando os Trópicos: um retrato intelectual de Gilberto Freyre. São Paulo: Editora Unesp.

Presidência da República (2003, jan. 9). Lei n 10.639/0311. Brasil: Casa Civil. Subchefia para Assuntos Jurídicos, Presidência da República.

Saviani, D. (2011). História das Ideias Pedagógicas no Brasil. Campinas: Autores Associados.

Schwarcz, L. M. (1993). O Espetáculo das Raças: cientistas, instituições e questão racial no Brasil do século XIX. São Paulo: Companhia das Letras.

Sito, L. (2014). Disputas y diálogos en torno al concepto de "acciones afirmativas" para la educación superior en Brasil. Universitas Humanisticas, 77(77), 251-273. 
Vigoya, M. V. y Espinel, S. L.. (2014). Cuestiones raciales y construcción de la Nación en tiempos de multiculturalismo. Universitas Humanisticas, 77(77), 13-31.

Villas Boas, G. (2006). Mudança Provocada: passado e futuro no pensamento sociológico brasileiro. Rio de Janeiro: Editora FGV.

\section{Cómo citar este artículo}

Oliveira, A. (2016). A relação entre raça e educação na obra de Gilberto Freyre. Universitas Humanística, 81, 305-329. http:/ / dx.doi.org/ 10.11144/Javeriana. uh81.rere 